\title{
Supply Constraints in Human Resources for Health May Limit Progress towards Universal Health Coverage in India: an Exploratory Study
}

\author{
Zodpey, S. $^{1}$ \& Hasan, H. $^{2}$
}

\begin{abstract}
Introduction: Some of the challenges that India faces to achieve universal health coverage include an imbalance in resource allocation, high out-of-pocket health expenditures, inflation in health spending, inadequate physical access to quality health services and lack of human resources. Among these, lack of skilled human resources is probably the most worrisome because it has led to a situation where the interventions that have proven benefits are also not universally available.
\end{abstract}

Objective: This article attempts to provide a brief overview on production of human resources for health $(\mathrm{HRH})$ in India, their geographical imbalances, and its implications on achieving universal health coverage.

Methods: We estimated the annual production of each category of $\mathrm{HRH}$ as the function of total number of recognized institutions and number of students graduating from these institutions. The information regarding number of recognized institutions and number of seats in those institutions was collected from the respective council (Medical Council of India, Indian Nursing Council, Pharmacy Council of India and others).

Results: Taking into account HRH requirements for a normative India district, our production estimates suggest that progress towards universal health coverage would be an uphill task, given existing shortages and iniquitous distribution of production and recruitment.

Conclusion: We recommend that the national government should develop a comprehensive national health policy of human resources for health and ensure financing for health workforce development.

Key words: Health Professionals

\section{Background}

Universal coverage is defined as securing access for all citizens to appropriate promotive, preventive, curative, and rehabilitative services at an affordable cost (WHO, 2005).

${ }^{1}$ Director- Indian Institute of Public Health- Delhi,

Director-Public Health Education,

Public Health Foundation of India, New Delhi

${ }^{2}$ Associate Professor,

Indian Institute of Public Health-Delhi,

Public Health Foundation of India, New Delhi

Corresponding Author:

Prof. Sanjay Zodpey, MD, PhD,

Director-Indian Institute of Public Health- Delhi,

Director-Public Health Education,

Plot No 47, Sector 44, Institutional Area,

Gurgaon-122002,

Haryana, India

Email:sanjay.zodpey@phfi.org,
Universal coverage not only incorporates complementary dimensions of financial risk protection i.e. the extent of population coverage (e.g. who is covered) but also the extent of health service coverage (e.g. what is covered) (Carrin et al., 2008). In India, the philosophy of universal health care was adopted by the national government as early as 1946 .

The Bhore Committee (1946) on the aims of progressive health service stated that "...service should be available to all citizens, irrespective of their ability to pay ..." (Bhore, 1946). The successive five-year development plans further provided necessary impetus by allocating financial resources, providing policy guidance and establishing necessary infrastructure. However, universal health coverage remained an elusive goal. The constitution of a High Level Expert Group (HLEG) on Universal Health Coverage (UHC) by the Planning Commission of India with the aim of incorporating a comprehensive plan for 
health within the 12th Five-Year Plan has brought universal health coverage back in focus.

The challenges that India face to achieve UHC include not only an imbalance in resource allocation, high out-of-pocket health expenditures, inflation in health spending and inadequate physical access to quality health services but also lack of human resources (Balarajan et al., 2011). Human resources for health $(\mathrm{HRH})$ are defined as the crucial core of a health system (Hongoro \& McPake, 2004) and their densities affect health outcomes independent of other determinants (Anand \& Barnighausen, 2004). Evidence suggests that not only health financing reforms and expansion of coverage of good-quality services is essential, ensuring adequate human resources are equally important to achieve universal coverage (Tangcharoensathien et al., 2011). Hence, health systems should be able to produce, recruit, train, and retain human resources with the necessary bundles of skills (Hongoro \& Normand, 2006). This paper reviews the Indian situation with regards to human resource for health from the perspective of availability and distribution in the health system and its implication on achieving universal health coverage in India.

\section{Methodology}

We have attempted to generate annual production estimates for different categories of $\mathrm{HRH}$ viz. doctors, nurses, auxiliary nurse midwifes, pharmacists and others. The annual estimates of each category of $\mathrm{HRH}$ is function of the total number of recognized institutions and number of students graduating from these institutions in the respective $\mathrm{HRH}$ categories. We collected information on a number of recognized institutions and the number of seats in these institutions, from the respective council (Medical Council of India, Indian Nursing Council, Pharmacy Council of India and others) websites (MCl., 2015, INC., 2015, PCI., 2015). Further, we analyzed reports published by the Ministry of Health and Family Welfare (MOHFW) and other relevant sources for published estimates (MOHFW, 2004, Rao et al., 2011; Sharma \& Zodpey, 2010). Finally, we triangulated all the data sources to arrive at representative production estimates for $\mathrm{HRH}$ in India.

\section{Results and Discussion}

We observed that in India, the departments of health at federal and state level are primarily concerned with recruitment, training and retention of human resources for health whereas production of $\mathrm{HRH}$ is a function of institutes of higher education (medical, nursing, pharmacy and allied health professionals colleges). The latest estimates on $\mathrm{HRH}$ in India suggest that there are slightly more than 8 health-care workers $(3 \cdot 8$ allopathic doctors, $2 \cdot 4$ nurses and nurse-midwives) per 10,000 population (Rao et al., 2011). These numbers are in sharp contrast to necessary requirements to achieve a minimum of 80 per cent coverage rate for deliveries by skilled birth attendants or for measles immunization (minimum of about 25 skilled health workers per 10,000 populations (doctors, nurses and midwives) (WHO, 2004).

We have estimated that with the current production scenario at the national level, the annual production estimate for medical graduates is around 51,979 from 387 medical colleges. Our annual production estimates for nursing professionals are around 100,000 professionals from 1,826 Nursing Colleges (BSc and MSc Nursing) and 3,247 nursing schools (General Nursing and Midwifery and Auxiliary Nurse and Midwives). For pharmacists, we estimated that annual production is approximately 40,000 and 50,000 for diploma and degree level pharmacists respectively from 1,627 pharmacy institutions approved by Pharmacy Council of India. Further, the annual production estimates for health and hospital administrators is around 3,500 health administrators and hospital administrators per year from more than 60 health and hospital management institutions recognized by the All India Council of Technical Education or Universities.

In addition, we observed that the distribution of majority of $\mathrm{HRH}$ producing institutions is largely concentrated in southern states of the country. This skewed distribution of medical institutions in the country is leading to geographical imbalance in production and recruitment of the health workforce. An earlier study has also reported considerable variation in the density of health workforce across the states in India. States with low health workforce density (10 16 workers per 10,000 population) tend to cluster in the belt running across north-central India. This spans the states of Rajasthan, Uttar Pradesh, Madhya Pradesh, Bihar, Jharkhand, Chhattisgarh, Assam and Meghalaya. These states also have low doctor density (3 to 6 doctors per 10,000 population) and low nurse and midwives density (less than 10 nurses and midwives per 10,000 population) (Rao et al., 2011). Further, we observed that production of $\mathrm{HRH}$ is a time intensive process given the long training periods for health professional (doctor, nurse, pharmacist, auxiliary nurse midwife and 
others). For example, duration may be as long as 18 months for an auxiliary nurse midwife (ANM) to 9 years for a medical specialist. In addition, we observed that instead of investing on planning and production of human resource for health to achieve health system goals the government is more engaged in regulation of $\mathrm{HRH}$ education.

In terms of demand estimation for $\mathrm{HRH}$ in India, it has been reported that a normative district with a 1.8 million population (1.13 billion population divided by 613 districts in India) would require approximately about 500 to 600 nursing and allied staff and 100 doctors by existing staffing practice. The requirement would increase by almost two and a half times to 1,400 nursing and allied staff and 300 doctors (Sundaraman \& Gupta, 2009) for a normative district under Indian Public Health Standards. In addition, a look into existing staffing pattern suggests that significant numbers of positions are already lying vacant in public health facilities across the country. The gap between staff in position and staff required at the end of the 11th Plan was 52 percent for ANM and nurses, 76 per cent for doctors, 88 percent for specialists and 58 percent for pharmacists. These shortages are attributed to delays in recruitment and to postings not being based on work-load or sanctions (GOI., 2013). Our assessment suggests that these existing shortages and disproportionate distribution of $\mathrm{HRH}$ across rural and urban health facilities and iniquitous distribution across public and private sector would make universal health coverage an uphill task.

The third global conference on human resource for health has also recognized that it is necessary to go beyond mere numbers by addressing gaps in distribution, competencies, quality, motivation and performance. The Recife Political Declaration on Human Resources for Health has recommended improved planning, education, management, governance and information systems to be implemented in accordance with countries' contexts and needs to address $\mathrm{HRH}$ challenges (WHO, 2014).

\section{Conclusion}

Our assessment suggests that health workforce planning is particularly complex because of changing needs and long training time for some professions. Further, market driven policies have led to gross imbalances in distribution of $\mathrm{HRH}$ in India geographically as well as across public and private sector. We recommend that the national government should take up a larger role in $\mathrm{HRH}$ forecasting, planning, production and recruitment to achieve the health system's objective and realize universal health coverage. For this, a comprehensive national health policy of human resources for health is the starting point followed by ensuring financing of workforce development and regulation of public and private sector.

In summary, the government should function as a leverage point for $\mathrm{HRH}$ development, through setting policies, securing financing, and regulating private sector.

\section{References}

Anand, S. \& Barnighausen T. (2004) Human resources and health outcomes: cross-country econometric study, Lancet, 364, pp 1603-1609.

Balarajan, Y., Selvaraj, S. \& Subramanian, S.V. (2011) Health care and equity in India, Lancet, 377, pp. 505-515.

Bhore, J. (1946) The Report of the Health Survey and Development Committee, Delhi: Government Of India press.

Carrin, G., Mathauer, I., Xu, K. \& Evans, D. B. (2008) Universal coverage of health services: tailoring its implementation, Bulletin of World Health Organization, 86, 11, pp. 857-863.

Government Of India (2013) Twelfth Five Year Plan (2012-2017) : Social Sectors, In: COMMISSION., P. (ed.). New Delhi: Planning Commission.

Hongoro, C. \& Mcpake, B. (2004) How to bridge the gap in human resources for health, Lancet, 364, 1451-1456.

Hongoro, C. \& Normand, C. (2006) Health Workers: Building and Motivating the Workforce. In: Jamison, D. T., Breman, J. G., Measham, A. R., Alleyne, G., Claeson, M., Evans, D. B., Jha, P., Mills, A. \& Musgrove, P. (Eds.) Disease Control Priorities in Developing Countries (2nd ed). Washington (DC): World Bank Publications.

Indian Nursing Council [Online] Available: http://www.indiannursingcouncil.org.[Accessed 3 May 2015].

MCI (2015) Medical Council of India [Online]. Available: http://www.mciindia.org. [Accessed 3 May 2015].

MOHFW (2004) Annual Report (2004-2005). In: WELFARE., M. O. H. A. F. (ed.). New Delhi. [Accessed 3 May 2015].

PCI (2015) Pharmacy Council of India. [Online]. Available: http://www.pci.nic.in. [Accessed 3 May 2015].

Rao, M., Rao, K. D., Kumar, A. K., Chatterjee, M. \& Sundararaman, T. (2011) Human resources for health in India, Lancet, 377, pp. 587-598. 
Report of the working group on medical education [Online] New Delhi. Available: http://www.knowledgecommission.gov.in/downloa ds/documents/wg_med.pdf [Accessed 5 August 2013].

Sharma, K. \& Zodpey, S. (2010) Need and opportunities for health management education in India, Indian Journal of Public Health, 54, pp. 8491.

Sundaraman, T. \& Gupta, G. (2009) Human Resource for Health: The Crisis, the NRHM Response and the Policy Options. New Delhi: NHSRC, Ministry of Health and Family Welfare.

Tangcharoensathien, V., Patcharanarumol, W., Ir, P., Aljunid, S. M., Mukti, A. G., Akkhavong, K., Banzone, E., Huong, D. B., Thabrany, H. \& Mills, A. (2011) Health-financing reforms in southeast Asia: challenges in achieving universal coverage, Lancet, 377, pp. 863-873.
World Health Organization (2004) WHO estimates of health personnel: physicians, nurses, midwives, dentists, pharmacists, Geneva: World Health Organization.

World Health Organization (2005) Sustainable health financing, universal coverage and social health insurance, Geneva: World Health Organization.

World Health Organization (2014) Human resources for health: foundation for universal health coverage and the post-2015 development agenda: report of the Third Global Forum on Human Resources for Health, Recife, Brazil. World Health Organization. 